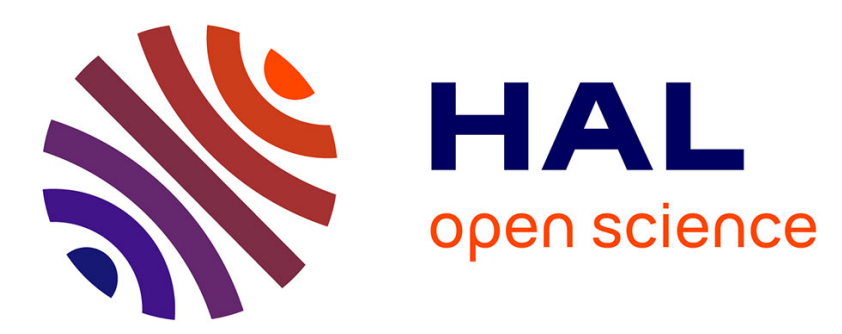

\title{
Design of a high gain single stage and single pass Nd:YVO4 passive picosecond amplifier
}

\author{
Xavier Délen, François Balembois, Patrick Georges
}

\section{To cite this version:}

Xavier Délen, François Balembois, Patrick Georges. Design of a high gain single stage and single pass Nd:YVO4 passive picosecond amplifier. Journal of the Optical Society of America B, 2012, 29 (9), pp.2339-2346. 10.1364/JOSAB.29.002339 . hal-00816870

\section{HAL Id: hal-00816870 \\ https://hal-iogs.archives-ouvertes.fr/hal-00816870}

Submitted on 23 Apr 2013

HAL is a multi-disciplinary open access archive for the deposit and dissemination of scientific research documents, whether they are published or not. The documents may come from teaching and research institutions in France or abroad, or from public or private research centers.
L'archive ouverte pluridisciplinaire HAL, est destinée au dépôt et à la diffusion de documents scientifiques de niveau recherche, publiés ou non, émanant des établissements d'enseignement et de recherche français ou étrangers, des laboratoires publics ou privés. 


\title{
Design of a high gain single stage and single pass $\mathrm{Nd}: \mathrm{YVO}_{4}$ passive picosecond amplifier
}

\author{
Xavier Délen, * François Balembois, and Patrick Georges \\ Laboratoire Charles Fabry, Institut d'Optique, CNRS, Univ Paris-Sud, 2 Av A. Fresnel, 91127 Palaiseau CEDEX, France \\ ${ }^{*}$ Corresponding author: xavier.delen@institutoptique.fr
}

Received April 30, 2012; revised July 9, 2012; accepted July 11, 2012;

posted July 12, 2012 (Doc. ID 167651); published August 7, 2012

\begin{abstract}
A detailed comparison of the influence of pumping wavelength and crystal doping concentration on the performance of $\mathrm{Nd}: \mathrm{YVO}_{4}$ amplifiers is developed through theoretical analysis. The effect of energy transfer upconversion and the strong temperature dependence of the emission cross section were taken into account. This study showed the interest of $808 \mathrm{~nm}$ pumping with low doping concentration crystals and the importance of the crystal temperature for the design of a high gain amplifier. Using these conclusions, we built a picosecond $\mathrm{Nd}_{\mathrm{YVO}} \mathrm{YV}_{4}$ master oscillator power amplifier reaching $10 \mathrm{~W}$ output power for only $50 \mathrm{~mW}$ of seed at $200 \mathrm{kHz}$ in a single pass, single stage configuration. With a pulse duration of $22 \mathrm{ps}$, it corresponds to an output pulse energy of $50 \mu \mathrm{J}$ and to a peak power of 2.3 MW. With a same setup, a single pass small signal gain over $45 \mathrm{~dB}$ has been measured, and near $50 \%$

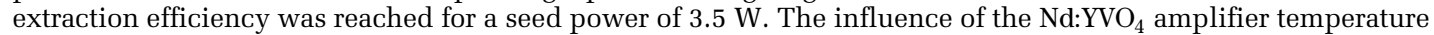
on the output power was also studied for different levels of gain saturation. (c) 2012 Optical Society of America OCIS codes: $\quad 140.3280,140.3430,140.3530,140.3613$.
\end{abstract}

\section{INTRODUCTION}

Picosecond laser emitting pulses in the tens of microjoules regime and working at hundreds of kilohertz repetition rates are in high demand in fields such as material processing. There are many different laser architectures that can be used to obtain such a source. Although a high power has been reached in the picosecond regime, systems based on fiber technology are limited in terms of peak power [1]. Ultralow repetition rate oscillators, as low as $1 \mathrm{MHz}$, can be developed [2], but those very long cavities are difficult to handle, leading to poor long-term stability. An alternative solution to access these regimes is mode locked cavity dumping, which has proven to be a successful technique. However, the output power decreased quickly with the repetition rate below $1 \mathrm{MHz}$ [3]. A master oscillator power amplifier (MOPA) combining a picosecond oscillator and a regenerative amplifier is often used in order to work at a lower repetition rate [4-6]. Regenerative amplifiers allow large repetition rate flexibility and good extraction efficiency without requiring a high energy level for the seed signal. The disadvantage of this solution is the complexity and the cost of the system. A passive amplifier, with a single pass in a single stage, can be considered as a simple and elegant solution if the gain of the medium is high enough. It can be the case for $\mathrm{Nd}$ doped yttrium vanadate crystal $\left(\mathrm{Nd}: \mathrm{YVO}_{4}\right)$ thanks to its huge cross section of $1210^{-19} \mathrm{~cm}^{2}$ at $1064 \mathrm{~nm}$. As an example, very high gain of around $50 \mathrm{~dB}$ has already been demonstrated in two stages $\mathrm{Nd}: \mathrm{YVO}_{4}$ grazing incidence slabs amplifier, showing the potential of direct amplification of a pulsed picked picosecond laser [7]. However, this system was working under quasi-continuous wave (qcw) pumping at low repetition rate $(100 \mathrm{~Hz})$ with a low extraction efficiency below 1\%. High repetition rate operation requires the use of cw pumping and increases considerably the thermal load in the crystal. This induces deleterious effects on the amplification performance: recent work showed that the emission cross section of the $\pi$ polarized $1064 \mathrm{~nm}$ line in $\mathrm{Nd}$ doped vanadate crystals decays rapidly with temperature [8-10]. This comes from both the emission line broadening and the spectral shift, which induces a detuning between the oscillator and the amplifier. The spectral shift is around $3 \mathrm{pm} /{ }^{\circ} \mathrm{C}$, whereas the emission linewidth at $1064 \mathrm{~nm}$ at room temperature is around $0.7 \mathrm{~nm}$ FWHM. As much as a $50 \%$ decrease of the emission cross section has been observed at a fixed wavelength for a temperature increase of only $60 \mathrm{~K}$. Consequently, the design of a simple and efficient $\mathrm{Nd}: \mathrm{YVO}_{4}$ amplifier operating at high repetition rate and high pump power level is challenging. To design such an amplifier, we propose some theoretical guidelines including a study of the influence of doping concentration and a theoretical comparison between several possible pumping wavelengths for high gain systems. We take into account the influence of concentration quenching and energy transfer upconversion (ETU) and the strong temperature dependence of the emission cross section. In the second part, we propose an experimental illustration with a longitudinally pumped single pass and single stage amplifier seeded by a pulse picked picosecond mode locked oscillator.

\section{THEORETICAL GUIDELINES}

The following sections describe theoretical calculations that are used to illustrate general trends in $\mathrm{Nd}: \mathrm{YVO}_{4}$ amplifiers using data and models available in the literature. Although several papers have been published on fluorescence quenching and ETU, there is a relatively wide uncertainty on the values measured in $\mathrm{Nd}: \mathrm{YVO}_{4}$, and our calculations are meant to study trends and not to calculate precise quantitative data.

\section{A. Influence of the Doping Concentration}

In order to reach a high gain and a high extraction efficiency in the amplifier, both a high inversion of population and a high 
emission cross section are required. Several processes can lead to nonradiative decays and therefore to a reduction of the upper level population. First of all, migration of excitation coupled with radiation trapping as well as cross relaxation are responsible for the concentration quenching effect. The probability of these decays increases with the doping concentration. This results in shorter excited state lifetime for highly doped samples and can be modeled in rate equations with a term similar to the one of spontaneous emission. Another process limiting the upper level population is ETU, which is due to an energy transfer between two ions in the excited state and results in the loss of one excited state ion energy. This transition probability increases with inversion of population and the doping concentration. In the case of migration assisted ETU, it can be modeled adding a quadratic term $\gamma n^{2}$ in the rate equation (1) giving the rate equation for the upper level in the case of an ideal four level system [11].

$$
\frac{d n}{d t}=-\frac{n}{\tau_{\mathrm{sp}}}-\frac{n}{\tau_{\mathrm{nr}}}-\gamma n^{2}+R-\sigma I,
$$

where $n$ is the upper level population, $\tau_{\mathrm{sp}}$ is the radiative lifetime, $\tau_{\mathrm{nr}}$ is the nonradiative lifetime, $\gamma$ is the upconversion coefficient, $R$ is the pumping rate, $\sigma$ is the laser emission cross section, and $I$ is the laser intensity. According to the literature, the inverse of the nonradiative lifetime increases quadratically with the doping concentration following Eq. (2) [12].

$$
\frac{1}{\tau_{\mathrm{nr}}}=\frac{1}{\tau_{\mathrm{sp}}}\left(\frac{C}{C_{q}}\right)^{2}
$$

where $C_{q}$ is the concentration quenching parameter and $C$ is the doping concentration in atomic percentage. For Nd: $\mathrm{YVO}_{4}$, a value of $C_{q}=3.1$ is given in the literature for a $\tau_{\mathrm{sp}}$ of $107 \mu \mathrm{s}$ [12]. Three different values can be found for the upconversion coefficient in $\mathrm{Nd}: \mathrm{YVO}_{4}$ at three different doping concentrations: $1.510^{-21} \mathrm{~m}^{3} / \mathrm{s}$ for $0.5 \%$ doping concentration [11], $310^{-21} \mathrm{~m}^{3} / \mathrm{s}$ for $1 \%$ doping concentration [13], and $710^{-21} \mathrm{~m}^{3} / \mathrm{s}$ for $1.5 \%$ doping concentration [14]. Assuming that a linear evolution of the ETU coefficient with the doping concentration is also verified for $\mathrm{Nd}$ doped vanadate, as has been observed for other $\mathrm{Nd}$ doped crystals $[\underline{15}, 16]$, an average upconversion coefficient per atomic percentage of doping concentration of $3.610^{-21} \mathrm{~m}^{3} / \mathrm{s} /$ at. \% can be deduced.

In order to compare the performance that can be obtained with different $\mathrm{Nd}^{3+}$ doping concentrations, we can define the effective lifetime of the laser transition upper level for a defined inversion of population $\tau_{\text {eff }}$ as given in Eq. (3). This effective lifetime seems to be a good parameter for a comparison between different doping concentrations in high gain amplifiers. Figure 1 shows the effective lifetime as a function of the doping concentration in atomic percentage for different population inversions. In order to describe general concepts, we define the upper electronic level population in atomic percentage $n^{\%}$ similarly as a doping concentration : $n^{\%}$ is defined as the ratio between the excited ions density $n$ and the ions density for a $1 \%$ atomic concentration $n_{t}^{1 \%}$ as described by Eq. (4). For example, a population of $n^{\%}=0.05 \%$ corresponds to an excited population being half the total population in a $0.1 \%$ doped crystal and to $10 \%$ of the total population in a $0.5 \%$ doped crystal. When there is no inversion of population,

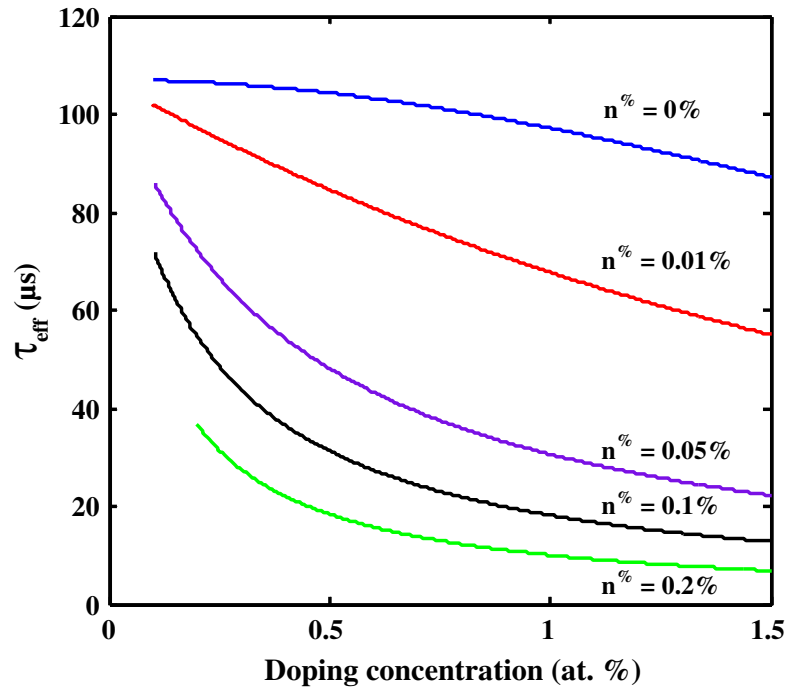

Fig. 1. (Color online) Effective excited state lifetime as a function of the doping concentration for different upper level population densities.

the effective lifetime decrease is only due to concentration quenching, but it decreases quickly with the inversion of population because of ETU. For a $0.1 \%$ doping concentration, the effective lifetime varies between $107 \mu \mathrm{s}$ and $72 \mu \mathrm{s}$ for a population inversion between $0 \%$ and $0.1 \%$, whereas it is between 104 and $31 \mu$ s for a $0.5 \%$ doping concentration and the same range of inversion of population. Considering high inversion of population of 0.2 at. \%, the maximal effective lifetime is only $37 \mu \mathrm{s}$. All these elements show that using a Nd:YVO $\mathrm{Y}_{4}$ crystal at a high level of inversion of population is in general very difficult to achieve, but it is easier using a low doping concentration. A major advantage of low doping concentration is that the inversion of population is intrinsically limited to a low value by the total population. Indeed, the saturation of absorption will induce a decrease of the absorption as the inversion of population increases.

$$
\begin{aligned}
\frac{1}{\tau_{\mathrm{eff}}} & =\frac{1}{\tau_{\mathrm{sp}}}+\frac{1}{\tau_{\mathrm{nr}}}+\gamma n, \\
n^{\%} & =\frac{n}{n_{t}^{1 \%}} .
\end{aligned}
$$

\section{B. Influence of the Pumping Wavelength}

Working with $\mathrm{Nd}: \mathrm{YVO}_{4}$ at high pump power, 880, 888, and $914 \mathrm{~nm}$ pumping wavelengths have been used in order to reduce the quantum defect and therefore the associated heat load [17-19]. The drawback with these pumping wavelengths is the low absorption, which is usually compensated by the use of higher doping concentration and longer crystals. Extra heat generation is associated to nonradiative decays and the different pumping wavelengths should be compared in terms of total heat load density and not only quantum effect. Indeed, as the doping concentration has to be increased for 880,888 , or $914 \mathrm{~nm}$ pumping wavelengths, the extra heat load associated to nonradiative decays will be larger for a given population inversion. As the effective upper state lifetime also decreases strongly with the doping concentration, a higher 
pumping rate will also have to be used to reach a given level of inversion of population. The heat load density $Q$ in watts per unit of volume can be calculated using Eq. (5), where $\sigma$ is the emission cross section at the laser wavelength, $I$ is the laser intensity, $\lambda_{p}$ is the pumping wavelength $(808,880$, or $888 \mathrm{~nm})$, $\lambda_{l}$ is the laser wavelength $(1064 \mathrm{~nm})$, and $\lambda_{f}$ is the average fluorescence wavelength $(1032 \mathrm{~nm})$ [12]

$$
Q=\frac{h c}{\lambda_{p}}\left(\frac{n}{\tau_{\mathrm{nr}}}+\gamma n^{2}\right)+\left(\frac{h c}{\lambda_{p}}-\frac{h c}{\lambda_{f}}\right) \frac{n}{\tau_{\mathrm{sp}}}+\left(\frac{h c}{\lambda_{p}}-\frac{h c}{\lambda_{l}}\right) \sigma I n
$$

We considered doping concentrations of $0.1 \%, 0.3 \%$, and $0.5 \%$ for 808,880 , and $888 \mathrm{~nm}$ pumping wavelengths, respectively. They correspond to typical doping concentrations that are referred to in the literature. For each population inversion, we calculated the heat load for a reference ideal case with $808 \mathrm{~nm}$ pumping without nonradiative transitions as given by Eq. (6) and used Eq. (7) to calculate the normalized heat load density $Q_{\text {norm }}$ as a function of the inversion of population (Fig. 2). This was done for the three different pumping wavelengths and their corresponding doping concentrations but also for different levels of laser intensity. In order to define
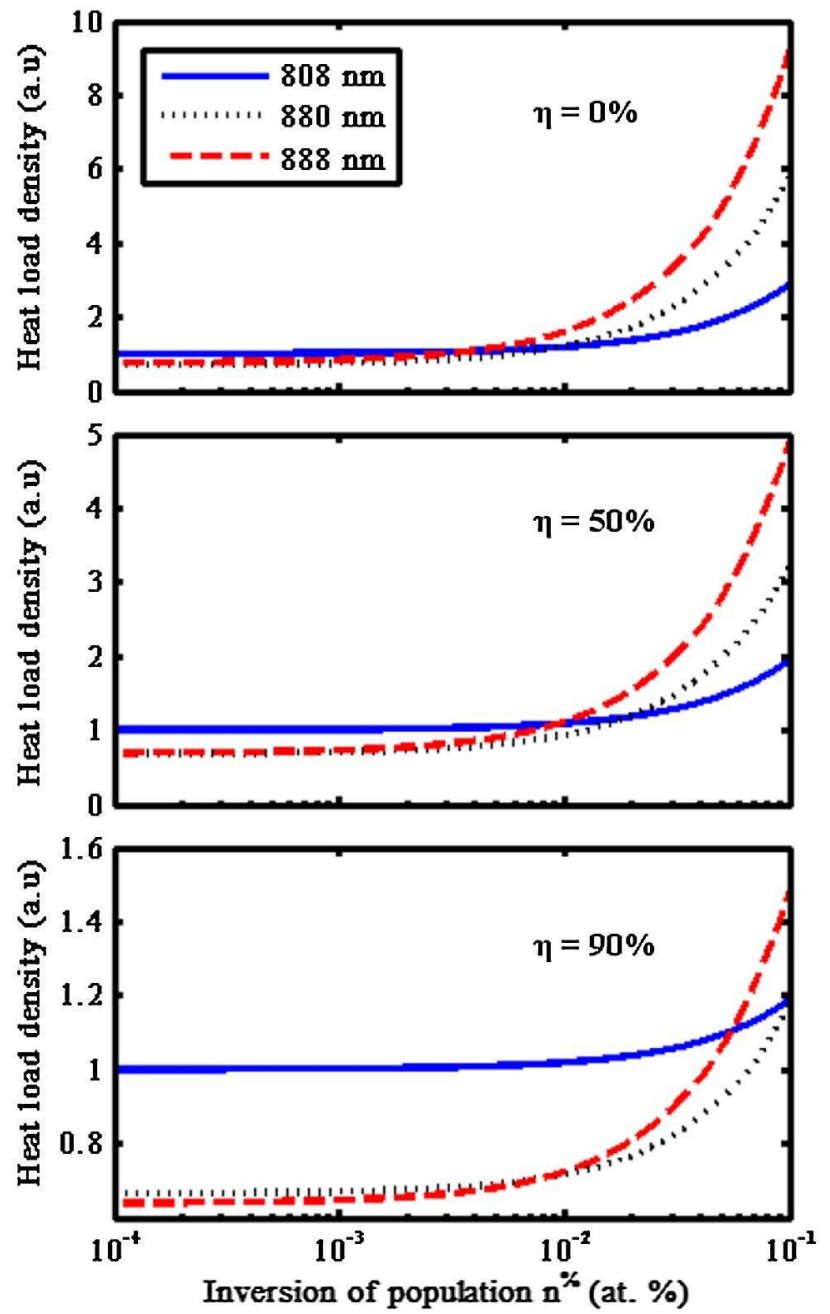

Fig. 2. (Color online) Normalized heat load density $Q_{\text {norm }}$ as a function of the population inversion for different extraction efficiencies. general concepts, we consider decay rates by stimulated emission corresponding to quantum extraction efficiencies $\eta$ of $0 \%$, $50 \%$, and $90 \%$ defined for an ideal crystal without concentration quenching nor ETU [Eq. ()] ]. Without any laser extraction, the heat load density is minimal for $808 \mathrm{~nm}$ pumping for an inversion above 0.01 at. \%. Even for the case of a $50 \%$ extraction, $808 \mathrm{~nm}$ pumping appears as the pumping wavelength for which the heat load density is the lowest for inversion of population above 0.02 at. \%. However, the advantage of higher pumping wavelength such as 880 or $888 \mathrm{~nm}$ is clear for low inversion of population and high extraction rates as shown by the results obtained for $\eta=90 \%$. In this last case, most decays are due to stimulated emission transitions at the laser wavelength, and the major part of the heat load is due to the quantum defect.

$$
\begin{aligned}
Q_{\mathrm{ref}}=\left(\frac{h c}{\lambda_{p}}-\frac{h c}{\lambda_{f}}\right) \frac{n}{\tau_{\mathrm{sp}}}+\left(\frac{h c}{\lambda_{p}}-\frac{h c}{\lambda_{l}}\right) \sigma I n \quad \text { with } \lambda_{p}=808 \mathrm{~nm} \\
Q_{\mathrm{norm}}=\frac{\mathrm{Q}}{\mathrm{Q}_{\mathrm{ref}}} \\
\eta=\frac{\sigma I n}{\frac{n}{\tau_{\mathrm{sp}}}+\sigma I n} .
\end{aligned}
$$

\section{Influence of the Temperature}

The extra heat load associated to nonradiative transitions does not only induce stronger thermal lenses but also changes the spectroscopic properties of the laser material. Especially, the emission cross section at $1064 \mathrm{~nm}$ strongly decreases with temperature [ $\underline{8}-10]$. As a consequence, nonradiative transitions will induce a gain reduction not only due to the population depletion but also due to the temperature increase. In order to obtain the small signal gain coefficient given by Eq. (9), we first need to calculate the population inversion using Eq. (10), where $R$ is the pumping rate defined as the number of absorbed pump photons per unit of time and volume. The heat load density can then be deduced with Eq. (5) and used to evaluate the temperature increase in the crystal. Assuming a radial heat transfer, a top hat pump beam of $r_{p}=200 \mu \mathrm{m}$ radius, and a crystal diameter of $3 \mathrm{~mm}\left(r_{c}=1.5 \mathrm{~mm}\right)$, the temperature difference between the center and the edge of the crystal can be calculated analytically [Eq. (11)] [20]. To simplify our model and be able to use this analytic expression of the temperature, we used an average value of the thermal conductivity $K_{c}$ of $10 \mathrm{~W} / \mathrm{m} / \mathrm{K}$ not accounting for the anisotropy of $\mathrm{YVO}_{4}[21,22]$. At first, we only considered the temperature increase inside the crystal $\Delta T_{c}$ and assumed a perfect contact between heat sink and crystal. The emission cross section at a fixed wavelength of $1064.1 \mathrm{~nm}$ for pi polarization was deduced from the formula given by Sato and Taira [10]. Figure $\underline{3}$ shows the evolution of the small signal gain coefficient as a function of the pumping rate for different pumping wavelengths assuming a doping concentration of, respectively, $0.1 \%, 0.3 \%$, and $0.5 \%$ for 808,880 , and $888 \mathrm{~nm}$ pumping. In order to emphasize tendencies, g0 was normalized to its maximum value and $R$ to a reference value $R_{\text {ref }}=1.410^{29} \mathrm{~s}^{-1} \mathrm{~m}^{-3}$ corresponding to $50 \mathrm{~W}$ on $400 \mu \mathrm{m}$ diameter and a $0.1 \%$ doped crystal in stationary state. It shows a 


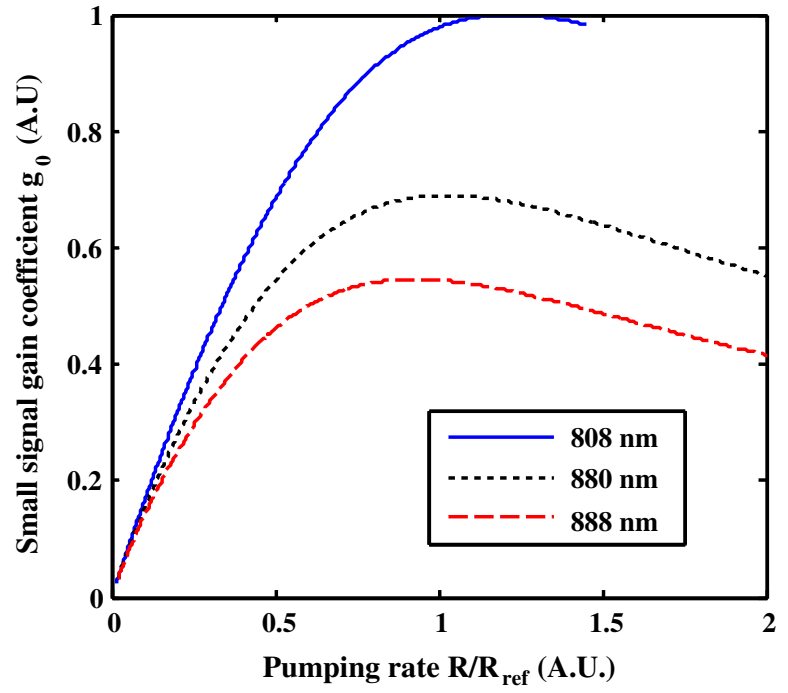

Fig. 3. (Color online) Small signal gain coefficient as a function of the pumping rate for $808 \mathrm{~nm}(0.1 \%), 880 \mathrm{~nm}(0.3 \%)$, and $888 \mathrm{~nm}(0.5 \%)$ pumping.

linear increase of the gain with pumping rate for low pumping rate levels at which nonradiative decays are negligible. At higher rates, the slope starts decreasing due to the emission cross section decrease with the temperature increase associated to higher pumping rates. For 880 and $888 \mathrm{~nm}$ pumping, the decrease is more significant due to both the emission cross section decrease and the population depletion induced by ETU. Our model even shows a decrease of the small signal gain coefficient for high pumping rates. The maximum small signal gains reached for 880 and $888 \mathrm{~nm}$ pumping are, respectively, $30 \%$ and $45 \%$ lower than the maximum reached for $808 \mathrm{~nm}$ pumping. Although it appears counterintuitive at first because of the higher quantum defect, these calculations show a clear advantage for $808 \mathrm{~nm}$ pumping under high inversion of population. The high absorption at this pumping wavelength allows the use of low doping concentration at which nonradiative decays are less probable thanks to the higher interion distances. It is then easier to reach high small signal gain using $808 \mathrm{~nm}$ pumping because of higher effective excited state lifetime.

$$
\begin{aligned}
g_{0} & =\sigma(T) n_{0}(R), \\
n_{0} & =\frac{1}{2 \gamma}\left[-\frac{1}{\tau_{\mathrm{sp}}}-\frac{1}{\tau_{\mathrm{nr}}}+\sqrt{\left(\frac{1}{\tau_{\mathrm{sp}}}+\frac{1}{\tau_{\mathrm{nr}}}\right)^{2}+4 \gamma R}\right], \\
\Delta T_{c} & =\frac{Q r_{p}^{2}}{4 K_{c}}\left[\ln \left(\frac{r_{c}^{2}}{r_{b}^{2}}\right)+1\right] .
\end{aligned}
$$

In order to maintain a low temperature inside the crystal to benefit from a high emission cross section, it is not only essential to limit the heat load associated to nonradiative effects, but it is also very important to obtain a good thermal contact between the crystal and the heat sink and to optimize the cooling system. Indeed, the gain in $\mathrm{Nd}: \mathrm{YVO}_{4}$ depends on the absolute temperature and not on the temperature gradient

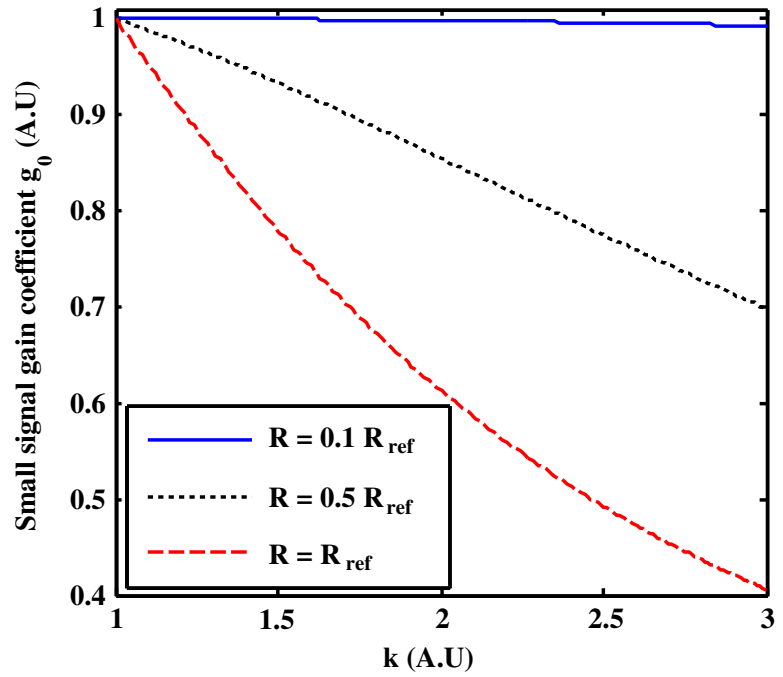

Fig. 4. (Color online) Small signal gain coefficient as a function of $k$ for different pumping rates.

inside the crystal like thermal lensing effects. Considering a water cooled system for example; we can distinguish the total temperature difference between the center of the pumped crystal $T_{c}$ and the incoming water $T_{w}$ and the intrinsic temperature increase inside the crystal between the center and the crystal edge $T_{e}$. In order to illustrate the importance of these parameters, we can define a simple parameter modeling the cooling system quality $k$ given by Eq. (12). For a water cooled system, we can anticipate typical $k$ values ranging between 1.1 and 1.5 depending on the contact quality between crystal and heat sink [23]. Considering air-cooled systems, much larger $k$ values can be anticipated, depending on the system. Figure 4 shows the relative variations of the small signal gain coefficient as a function of this parameter for three different pumping rates. For a fixed water temperature of $5{ }^{\circ} \mathrm{C}$, given $k$ and $R$ we calculated the temperature in the center of the crystal using Eqs. (11) and (12), the temperature dependent cross section and the small signal gain. At low pumping rates, the heat load stays small and the cooling system quality has a very weak influence on the small signal gain. However, considering high pumping rates, the cooling system quality has a huge impact on the small signal gain coefficient showing the large influence of technological choices for the cooling system of an amplifier.

$$
k=\frac{T_{c}-T_{w}}{T_{c}-T_{e}} .
$$

To summarize, our theoretical approach shows clearly that $808 \mathrm{~nm}$ pumping is more efficient as far as significant gain is requested. Moreover, the study shows the deleterious effect of temperature increase on the gain, meaning that crystal cooling needs to be considered carefully.

\section{EXPERIMENT}

\section{A. Setup}

In order to illustrate the high potential of low doping concentration $\mathrm{Nd}: \mathrm{YVO}_{4}$ pumped at $808 \mathrm{~nm}$ and its use as a high gain amplifier, we have built a simple amplifier setup. Figure 5 shows the experimental setup used for this work. The amplifier 


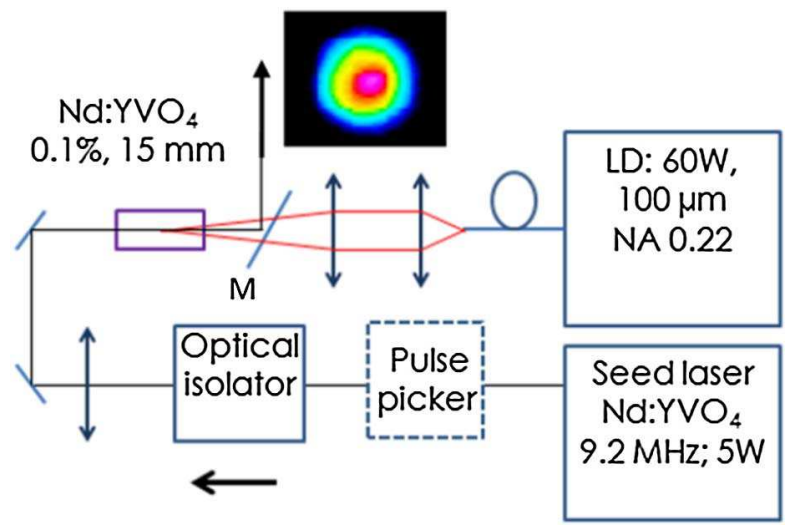

Fig. 5. (Color online) Experimental setup of our single stage, single pass amplifier. LD stands for laser diode. Beam profile obtained for a maximum pump power and a seed of $50 \mathrm{~mW}$ at $200 \mathrm{kHz}$ repetition rate.

was kept as simple as possible with a single pass for both the pump and the signal in longitudinal contrapropagative pumping configuration. As shown in Section 2, a low doping concentration allows us to reduce nonradiative effects and to spread the heat load over a longer length and to reduce the absolute temperature increase in the crystal. This way, the emission cross section decrease and the gain spectral shift of the amplifier are limited. The two crystal faces were coated with an antireflective coating highly transparent at $808 \mathrm{~nm}$ and at $1064 \mathrm{~nm}$ ( $R<0.1 \%)$. A high brightness fiber coupled laser diode emitting a maximum output power of $60 \mathrm{~W}$ at $808 \mathrm{~nm}$ out of a $100 \mu \mathrm{m} 0.22$ NA fiber corresponding to a pump beam $M^{2}$ of 43 was used for pumping. Using two doublets of focal length 60 and $200 \mathrm{~mm}$, the pump light was collimated and focused into the laser crystal over an expected diameter of $330 \mu \mathrm{m}$ given by the fiber core diameter and the magnification. The exact position of the pump waist along the optical axis was chosen in order to maximize the performance. The pump absorption was $75 \%$. The active medium was a $15 \mathrm{~mm}$ long and $0.1 \%$ doped $\mathrm{Nd}: \mathrm{YVO}_{4}$ crystal mounted between two water cooled heat sinks using indium foils carefully design to limit the temperature difference between the crystal and its mount. In order to test the efficiency of our cooling system, we used a setup very similar to the one used by Chénais et al. [23]; a thermal camera and a ZnSe dichroïc beam splitter were used to obtain the temperature map of the crystal in order to monitor the thermal contact quality while mounting the crystal. For about $50 \mathrm{~W}$ of incident pump power on a spot diameter around $330 \mu \mathrm{m}$, the crystal edges were measured to be about $30{ }^{\circ} \mathrm{C}$ above water temperature. The temperature gradient between the edge and the center of the crystal was around $40{ }^{\circ} \mathrm{C}$. A heat transfer coefficient of $0.7 \mathrm{~W} / \mathrm{cm}^{2} / \mathrm{K}$ can be estimated using these two values. This is close to the value of $0.9 \mathrm{~W} / \mathrm{cm}^{2} / \mathrm{K}$ measured with indium foil contact during a previous study [23].

In order to start the amplification process with significant pulse energy, we designed a long cavity picosecond oscillator $[2,3]$. It included a Herriot-style multiple-pass cavity (MPC) made of two large mirrors (plane mirror and $R=4 \mathrm{~m}$ ), leading to a $16.3 \mathrm{~m}$ long cavity and to a repetition rate of $9.2 \mathrm{MHz}$. Passive modelocking was obtained using a semiconductor saturable absorber (SESAM) with a saturation fluence of $70 \mu \mathrm{J} / \mathrm{cm}^{2}$ and a modulation depth of $1.2 \%$. The gain medium was a $3 \times 3 \times 10 \mathrm{~mm} \mathrm{Nd}: \mathrm{YVO}_{4}$ crystal with a doping concentration of $0.1 \%$ pumped at $30 \mathrm{~W}$ by a fiber coupled laser diode at $808 \mathrm{~nm}$ ( $400 \mu \mathrm{m}$ core diameter $0.22 \mathrm{NA})$. For an output coupler transmission of $15 \%$, the oscillator delivered more than $5 \mathrm{~W}$ of output power with a pulse energy of $0.54 \mu \mathrm{J}$ and a pulse duration of $22 \mathrm{ps}$. The output beam was nearly diffraction limited with an $M^{2}$ value below 1.3 measured using the second moment width.

Before amplification, we used an acousto-optic modulator as a pulse peaker in order to decrease the repetition rate. The signal beam was sent in the amplifier in contrapropagative configuration with respect to the pump, and its waist diameter was $400 \mu \mathrm{m}$ in the crystal. The input polarization of the signal beam was adjusted using a half wave-plate. The flat dichroïc mirror M at the output of the amplifier was HR coated for $1064 \mathrm{~nm}$ and HT coated for $808 \mathrm{~nm}$ for an incidence angle of $45^{\circ}$. The absorbed pump power was monitored during the experiment. Due to the extremely high gain that can be obtained in the crystal at high pump power, we observed parasitic oscillation between the two faces of the $\mathrm{Nd}: \mathrm{YVO}_{4}$ without seed power, despite their antireflection coating. For a maximum pump power and a pump beam perpendicular to the two crystal faces, the parasitic laser effect was observed at $1064 \mathrm{~nm}$. In order to separate this laser effect from the amplified signal and be able to make sure the parasitic oscillation disappears with the signal seeding, the laser crystal was slightly tilted by about $2^{\circ}$ so that the amplified beam and the parasitic laser beam were angularly separated.

\section{B. Experimental Results}

At first, the pulses were seeded at full repetition rate $(9.2 \mathrm{MHz})$ without the pulse picker in order to be able to study the performance of the amplifier for a wide range of input powers. The evolution of the output power as a function of the injected power was measured for injected power ranging between $26 \mathrm{~mW}$ and $3.5 \mathrm{~W}$, as shown in Fig. $\underline{6}$. The parasitic laser effect was observed for injected power below $26 \mathrm{~mW}$. Because of the gain saturation, this parasitic laser effect disappeared at higher signal level. During this experiment, the temperature of the water in the cooling system of the crystal was set at $5{ }^{\circ} \mathrm{C}$. With an output power of $8.9 \mathrm{~W}$, a maximum gain of about

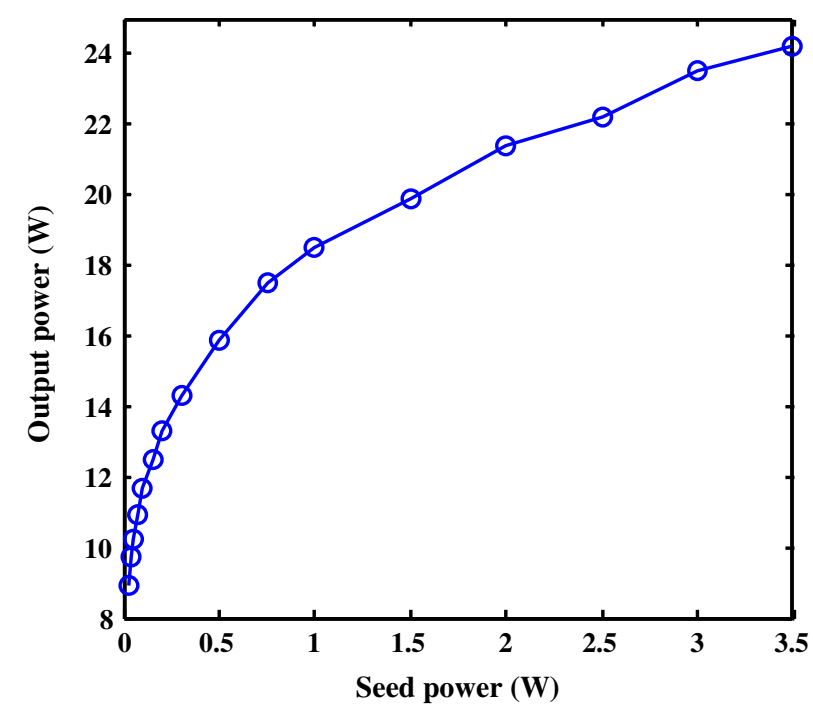

Fig. 6. (Color online) Output power as a function of the seed power for a repetition rate of $9.2 \mathrm{MHz}$ and a cooling water temperature of $5{ }^{\circ} \mathrm{C}$. 


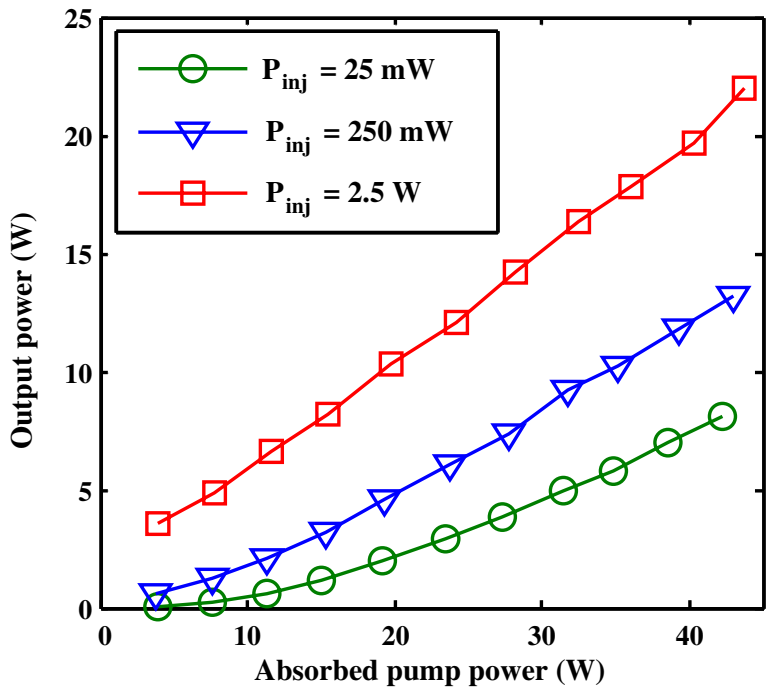

Fig. 7. (Color online) Output power as a function of the absorbed pump power for a repetition rate of $9.2 \mathrm{MHz}$ and a cooling water temperature of $17^{\circ} \mathrm{C}$

440 corresponding to $26 \mathrm{~dB}$ was measured for an injected power of $26 \mathrm{~mW}$. In this configuration, the total absorbed power was $40.5 \mathrm{~W}$, resulting in an extraction efficiency of $22 \%$. It reached $49 \%$ for $3.5 \mathrm{~W}$ injected power and $24.2 \mathrm{~W}$ of output power. Due to the increase of the extraction efficiency with the injected power, the inversion of population decreased and the saturation of absorption was reduced for the pump. This resulted in an increase of $5 \%$ of the absorbed pump power for a seed power increasing from $26 \mathrm{~mW}$ to $3.5 \mathrm{~W}$. In Fig. 7, we show the output power as a function of the absorbed pump power for three different values of the seeded power. This time, the cooling temperature was set at $17{ }^{\circ} \mathrm{C}$ in order to avoid water condensation on the crystal faces at low pump power. The three curves do not show any sign of rollover, which indicates a limited effect of the temperature increase. Deleterious effects of temperature increase induced by the pump are kept under control in our setup. The foregoing also reveals the potential of this type of system at higher pump power level.

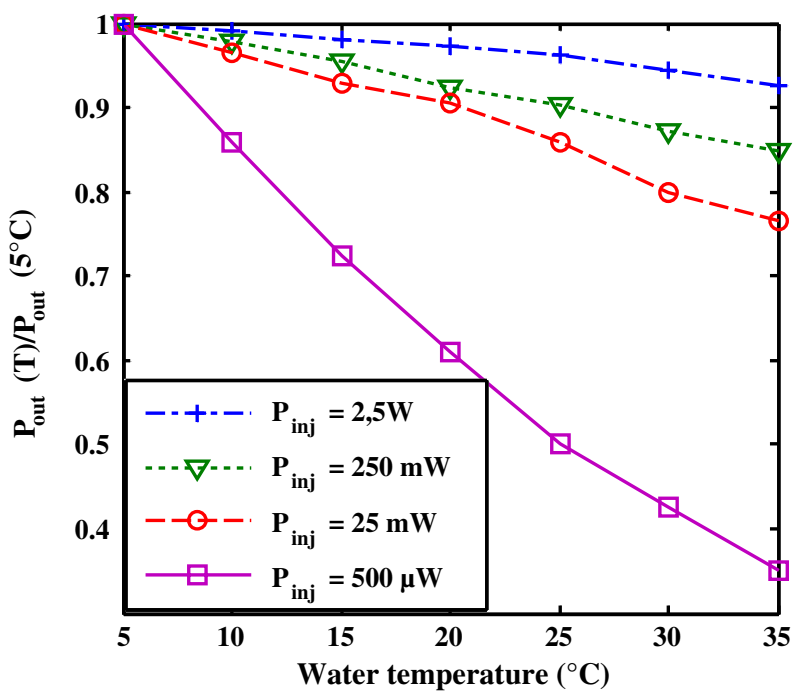

Fig. 8. (Color online) Evolution of the output power with the cooling temperature of the amplifier crystal for a repetition rate of $9.2 \mathrm{MHz}$.
Figure 8 shows the evolution of the output power with the temperature of the water circulating in the heat sinks. Variations of the absorbed pump power were also observed with the temperature. They can be induced by the lower extraction level, which results in a saturation decrease, but also by absorption cross section variation at the pump wavelength. In order to compensate for these effects, the pump power was adjusted to operate at a fixed absorbed pump power of $38 \mathrm{~W}$. The results are shown for four levels of injected pump power: $25 \mathrm{~mW}, 250 \mathrm{~mW}$, and $2.5 \mathrm{~W}$. For a high saturation of the gain, the output power decrease was only of about $7 \%$ for a temperature increase of $30{ }^{\circ} \mathrm{C}$. However, this decrease reached respectively $15 \%, 24 \%$, and $65 \%$ for input power of $250 \mathrm{~mW}$, $25 \mathrm{~mW}$, and $500 \mu \mathrm{W}$. The influence of the temperature on the output power varies strongly with the gain saturation level. It is most important for the low saturation regime close to the small signal gain regime. This result shows the significant impact of temperature on such a high gain system and the influence of the gain saturation level on this decrease similar to observations done in $\mathrm{Nd}: \mathrm{YVO}_{4}$ oscillators [9].

In order to be able to study the evolution of the gain with a weak seed power, we increased the tilt of the crystal to $15^{\circ}$. This way, it was possible to work at maximum pump power without observing any parasitic laser effect. It also minimized the power extraction of the beam reflected by the antireflective coating of the crystal. The seed power was modulated using a half wave-plate and a polarizer. Several diaphragms were used in order to minimize the collection of amplified spontaneous emission and fluorescence by our power meter. Figure 9 shows the gain in decibels as a function of the seed power, which is given in watts. The small signal gain is larger than $45 \mathrm{~dB}$. Considering a Gaussian beam profile for both the pump and the signal and adjusting the beam divergence according to the beam $M^{2}$, we performed numerical resolution of rate equations in order to calculate the expected small signal gain in our system using the method described in [14]. We did this calculation for an ideal case without taking into account ETU or the temperature dependance of the emission cross section and found an expected small signal gain

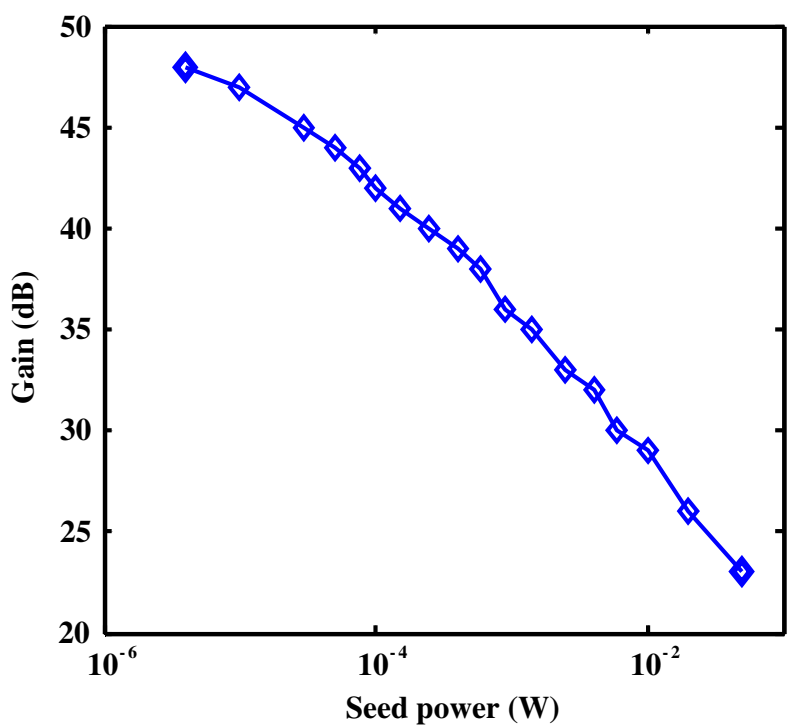

Fig. 9. (Color online) Evolution of the gain with the seed power for a repetition rate of $9.2 \mathrm{MHz}$ and a cooling water temperature of $5{ }^{\circ} \mathrm{C}$. 
between $47 \mathrm{~dB}$ and $53 \mathrm{~dB}$, taking into account the uncertainty of the beam sizes. This value is close to the experimental one, and it indicates that the influence of nonradiative effects such as upconversion have a weak influence in our configuration. This is possible thanks to the low doping concentration of our sample and to the efficient cooling system.

Finally, we used the pulse picker in order to decrease the pulse repetition rate down to $200 \mathrm{kHz}$. The amplifier was then injected by an average power of $50 \mathrm{~mW}$. Operating at a water temperature of $5{ }^{\circ} \mathrm{C}$, the amplifier gave an output power up to $10 \mathrm{~W}$. It corresponds to a peak power of $2.3 \mathrm{MW}$ and a pulse energy of $50 \mu \mathrm{J}$. The spatial profile of the output beam is shown in Fig. 5, and the output beam quality $M^{2}$ factor was 1.4

\section{CONCLUSION}

In this study, different pumping wavelengths and doping concentrations of Nd: $\mathrm{YVO}_{4}$ were compared theoretically. Taking into account the influence of fluorescence quenching, ETU, and the temperature dependency of the emission cross section at $1064 \mathrm{~nm}$, we evaluated the potential of $\mathrm{Nd}: \mathrm{YVO}_{4}$ crystals for high gain amplifier design under 808, 880, and $888 \mathrm{~nm}$. First, we have shown the significant decrease of the effective excited state lifetime with the doping concentration due to concentration quenching and ETU. This demonstrates the interest of low doping concentration, which implies the use of $808 \mathrm{~nm}$ despite a higher quantum defect than at 880 or $888 \mathrm{~nm}$. Indeed, as nonradiative transition rates strongly increase with the doping concentration, we showed that the overall heat load is counterintuitivelly lower at $808 \mathrm{~nm}$ than at 880 or $888 \mathrm{~nm}$ even at significant extraction efficiency, providing that high population inversion is requested. The small signal gain coefficient evolution with the pumping rate was also studied, accounting for the upper level population depletion by nonradiative transitions and the influence of temperature on the emission cross section for the laser transition. This study shows a maximum gain coefficient found for $808 \mathrm{~nm}$ pumping more than $40 \%$ and $55 \%$ higher than for 880 and $888 \mathrm{~nm}$ pumping. For high pumping rates, the gain coefficient even starts decreasing because of the influence of temperature on the emission cross section. Finally, we have underlined the strong impact of the crystal thermal mounting and cooling system quality on performance. In order to demonstrate the advantage of $808 \mathrm{~nm}$ pumping and low doping concentration, we illustrated these theoretical guidelines with a high gain single stage, single pass amplifier pumped at $808 \mathrm{~nm}$ and using a low doping concentration of $0.1 \%$. We obtained output powers ranging from 8.9 to $24.2 \mathrm{~W}$ for a seeding power between $26 \mathrm{~mW}$ and $3.5 \mathrm{~W}$ for a cooling water temperature of $5{ }^{\circ} \mathrm{C}$. An extraction efficiency near $50 \%$ was reached at maximum seed power. A single pass small signal gain over $45 \mathrm{~dB}$ was measured in this system. At $200 \mathrm{kHz}, 50 \mu \mathrm{J}$ pulses were produced with a peak power above $2 \mathrm{MW}$ and an extraction efficiency around 25\%. By tuning the cooling water temperature, we showed the large sensibility of the $\mathrm{Nd}: \mathrm{YVO}_{4}$ amplifier to the temperature, demonstrating that the cooling has to be designed carefully in order to exploit this gain medium at its full potential. Our system performance is close to what can be obtained with a regenerative amplifier but with a much simpler design in a single stage and single pass amplifier. Compared to a fiber amplifier, it has the advantage of a much higher limit in terms of peak power, thanks to the large signal beam diameter.

\section{ACKNOWLEDGMENTS}

Xavier Délen acknowledges the Direction Générale de l'Armement (DGA) for the funding of his Ph.D.

\section{REFERENCES}

1. D. J. Richardson, J. Nilsson, and W. A. Clarkson, "High power fiber lasers: current status and future perspectives," J. Opt. Soc. Am. B 27, B63-B92 (2010).

2. D. N. Papadopoulos, S. Forget, M. Delaigue, F. Druon, F. Balembois, and P. Georges, "Passively mode-locked diodepumped $\mathrm{Nd}: \mathrm{YVO}_{4}$ oscillator operating at an ultralow repetition rate," Opt. Lett. 28, 1838-1840 (2003).

3. U. Wegner, J. Meier, and M. J. Lederer, "Compact picosecond mode-locked and cavity-dumped $\mathrm{Nd}: \mathrm{YVO}_{4}$ laser,” Opt. Express 17, 23098-23103 (2009).

4. M. Siebold, M. Hornung, J. Hein, G. Paunescu, R. Sauerbrey, T. Bergmann, and G. Hollemann, "A high-average-power diodepumped $\mathrm{Nd}: \mathrm{YVO}_{4}$ regenerative laser amplifier for picosecondpulses,” Appl. Phys. B 78, 287-290 (2004).

5. M. Luehrmann, C. Theobald, R. Wallenstein, and J. A. L'huillier, "High energy cw-diode pumped $\mathrm{Nd}_{\mathrm{YVO}} \mathrm{VV}_{4}$ regenerative amplifier with efficient second harmonic generation," Opt. Express 17, 22761-22766 (2009).

6. J. Kleinbauer, R. Knappe, and R. Wallenstein, "13 W picoseconds $\mathrm{Nd}: \mathrm{GdVO}_{4}$ regenerative amplifier with $200 \mathrm{kHz}$ repetition rate," Appl. Phys. B 81, 163-166 (2005).

7. A. Agnesi, L. Carr, F. Pirzio, D. Scarpa, A. Tomaselli, G. Reali, C. Vacchi, and C. Braggio, "High-gain diode-pumped amplifier for generation of microjoule-level picosecond pulses," Opt. Express 14, 9244-9249 (2006).

8. G. Turri, H. P. Jenssen, F. Cornacchia, M. Tonelli, and M. Bassi, "Temperature-dependent stimulated emission cross section in $\mathrm{Nd}^{3+}: \mathrm{YVO}_{4}$ crystals,” J. Opt. Soc. Am. B 26, 2084-2088 (2009).

9. X. Délen, F. Balembois, and P. Georges, "Temperature dependence of the emission cross section of $\mathrm{Nd}: \mathrm{YVO}_{4}$ around $1064 \mathrm{~nm}$ and consequences on laser operation," J. Opt. Soc. Am. B 28, 972-976 (2011).

10. Y. Sato and T. Taira, "Temperature dependencies of stimulated emission cross section for Nd-doped solid-state laser materials," Opt. Mater. Express 2, 1076-1087 (2012).

11. Y. F. Chen, C. C. Liao, Y. P. Lan, and S. C. Wang, "Determination of the Auger upconversion rate in fiber-coupled diode end-pumped Nd:YAG and Nd:YVO 4 crystals,” Appl. Phys. B 70, 487-490 (2000).

12. Z. Huang, Y. Huang, Y. Chen, and Z. Luo, "Theoretical study on the laser performances of $\mathrm{Nd}^{3+}: \mathrm{YAG}$ and $\mathrm{Nd}^{3+}: \mathrm{YVO}_{4}$ under indirect and direct pumping," J. Opt. Soc. Am. B 22, 2564-2569 (2005).

13. L. Meilhac, G. Pauliat, and G. Roosen, "Determination of the energy diffusion and the Auger upconversion constants in a Nd: $\mathrm{YVO}_{4}$ standing wave laser," Opt. Commun. 203, 341-347 (2002).

14. X. Délen, F. Balembois, O. Musset, and P. Georges, "Characteristics of laser operation at $1064 \mathrm{~nm}$ in $\mathrm{Nd}: \mathrm{YVO}_{4}$ under diode pumping at 808 and 914 nm," J. Opt. Soc. Am. B 28, 52-57 (2011).

15. S. Guy, C. L. Bonner, D. P. Shepherd, D. C. Hanna, and A. C Tropper, "High-inversion densities in Nd:YAG: upconversion and bleaching," IEEE J. Quantum Electron. 34, 900-909 (1998).

16. C. Jacinto, S. L. Oliveira, T. Catunda, A. A. Andrade, J. D. Myers and M. J. Myers, "Upconversion effect on fluorescence quantum efficiency and heat generation in $\mathrm{Nd}^{3+}$-doped materials," Opt Express 13, 2040-2046 (2005).

17. R. Lavi, S. Jackel, Y. Tzuk, M. Winik, E. Lebiush, M. Katz, and I. Paiss, "Efficient pumping scheme for neodymium-doped materials by direct excitation of the upper lasing level," Appl. Opt. 38, 7382-7385 (1999).

18. L. McDonagh, R. Wallenstein, R. Knappe, and A. Nebel, "Highefficiency $60 \mathrm{~W} \mathrm{TEM}_{00} \mathrm{Nd}: \mathrm{YVO}_{4}$ oscillator pumped at $888 \mathrm{~nm}$," Opt. Lett. 31, 3297-3299 (2006). 
19. D. Sangla, M. Castaing, F. Balembois, and P. Georges, "Highly efficient $\mathrm{Nd}: \mathrm{YVO}_{4}$ laser by direct in-band diode pumping at 914 nm," Opt. Lett. 34, 2159-2161 (2009).

20. Y. F. Chen, T. M. Huang, C. F. Kao, C. L. Wang, and S. C. Wang, "Optimization in scaling fiber-coupled laser-diode end-pumped lasers to higher power: Influence of thermal effect," IEEE J. Quantum Electron. 33, 1424-1429 (1997).

21. J. Morikawa, C. Leong, T. Hashimoto, T. Ogawa, Y. Urata, S. Wada, M. Higuchi, and J. Takahashi, "Thermal conductivity/ diffusivity of $\mathrm{Nd}^{3+}$ doped $\mathrm{GdVO}_{4}, \mathrm{YVO}_{4}, \mathrm{LuVO}_{4}$, and $\mathrm{Y}_{3} \mathrm{Al}_{5} \mathrm{O}_{12}$ by temperature wave analysis," J. Appl. Phys. 103, 063522 (2008).

22. Y. Sato and T. Taira, "The studies of thermal conductivity in $\mathrm{GdVO}_{4}, \mathrm{YVO}_{4}, \mathrm{Y}_{3} \mathrm{Al}_{5} \mathrm{O}_{12}$ measured by quasi-one dimensional flash method," Opt. Express 14, 10528-10536 (2006).

23. S. Chénais, S. Forget, F. Druon, F. Balembois, and P. Georges, "Direct and absolute temperature mapping and heat transfer measurements in diode-end-pumped Yb:YAG," Appl. Phys. B 79, 221-224 (2004). 